\title{
International Assignments - Extending An Organisational Value Framework
}

\section{Purpose}

To present a framework relating to the organizational value of international assignments (IAs). This extends the existing framework by Lepak, Smith and Taylor (2007) and applies to other fields researching questions of value.

\section{Design/methodology/approach}

This is a conceptual paper that applies new thinking to the critical practical and theoretical issue of organisational value in Global Mobility (GM) and International Business (IB) literature. The Lepak et al. (2007) framework is explained, used and extended to appraise the value of IAs to organizations.

\section{Findings}

The primary contribution is the establishment of a value framework within which future IA research can position itself, refining extant measures and thereby enabling greater cohesion in future studies. The secondary contribution, impacting beyond the field of $\mathrm{GM}$, is the development of this framework including: the identification and discussion of value itself; the significance of organizational sub-levels; the extension of the definitions of isolating mechanisms and competition to explicate value capture; the importance of temporal analysis; and the inclusion of value assessment.

\section{Research limitations/implications}

The paper is limited by its application to IAs at the organizational level only. However, the relationship with other levels is also explored. Research within different contexts or focusing on the other levels of value will increase the understanding of value. 


\section{Practical implications}

Definitions of the value of IAs are extended and practitioner implications are discussed.

\section{Originality/value}

A new framework for evaluating the organizational value of IAs and new definitions to enable this value to be assessed are produced.

\section{Keywords:}

Value, Value Creation, International Assignments, International Business 


\section{Introduction}

The value of international assignments (IAs) to organisations is a nascent field of research that has recently grown. First, in the Global Mobility (GM) field, triggered by the important paper on ROI by McNulty and Tharenou (2004). Second, research in the broader International Business (IB) and leadership literature has considered the value of IAs in relation to recipient subsidiaries (see, for example Geringer and Hebert, 1989; Lyles and Salk, 1996) and the impact of CEO IA experience (see, for example Daily, Certo and Dalton, 2000). These different bodies of literature, involving many different theoretical constructs and different perspectives on organizational value, tend to remain separate despite their overlapping interests in IAs and value. Indeed the IB literature, whilst more abundant and mature than the ROI literature, tends to focus on recipient subsidiaries with little reference to the broader implications such as the impact on the sending (home) organization or the individual assignee (see, for example Konopaske, Werner and Neupert, 2002). Similarly, for example, whilst the ROI literature critically identifies the interaction between the value to the organization and that to the individual (see, for example McNulty and De Cieri, 2016) this does not consider the relationship with value to society nor the different legal entities in the organization.

As the global shortage of talent continues to be reported (Collings, Mellahi and Cascio, 2019) the IA is one potential solution as it enables the movement of employees around the world, both to develop and allocate talent (Edström and Galbraith, 1977). However, judging the effectiveness of such a solution requires an understanding of the true value involved to the organisations involved, i.e. including all relevant entities both separately and in combination. Accordingly, an effective conceptualization is needed to bring together the many different research findings to date with a specific focus on this organizational level of value for international assignments.

In line with calls for further research into the organizational value of IAs (Baruch, Altman and Tung, 2016; Bonache and Zárraga-Oberty, 2017), we provide a 
framework within which scholars can position their research. This is achieved by the applications and extension of an existing influential model of value creation and value capture, by Lepak, Smith and Taylor (2007), to the field. In so doing we provide a guiding framework within which future research into this important topic can be placed, thereby enabling scholars to engage with the existing literature and build a cohesive body of research moving forward. Equally important, this extended framework offers benefits to other fields of research interested in questions of value.

Lepak et al. (2007) aimed to address the confusion regarding the concept of value creation within the management literature by dividing it into value creation and value capture. In doing this, Lepak et al. built upon the economic constructs of use value and exchange value (Bowman and Ambrosini, 2000a) to define value creation and to stress the significance of separating the content of any value created (what is value?), the process of its creation and the mechanisms through which that value is retained or captured. They explored how the explanations of these issues are dependent upon the level of analysis and the theoretical perspective of the investigation, acknowledging that 'additional conceptual thought and development' is appropriate to test their ideas (Lepak, Smith and Taylor, 2007, p.191).

The influence and academic value of Lepak et al.'s (2007) paper is demonstrated through its growing usage. With over 460 citations in its first 13 years it has been referenced in a wide range of journals including Journal of Management, Academy of Management Review and Journal of Business Ethics. Already in 2020 researchers have drawn on the paper across a wide range of fields including Entrepreneurship and Innovation (Nair and Blomquist, 2020), Human Resource Management (Collins, 2020), Corporate Social Responsibility (Jia, 2020) and Research \& Development (Olk and West, 2020).

We focus our framework here on examining direct relationships between organizational value and IAs for assigned expatriates. We exclude self-initiated expatriates as the investment dynamics and long-term employee transfer expectations are distinctly different. IAs are otherwise defined here in line with 
McNulty and Brewster's (2017, p.20) definition of 'business expatriates' as events including 'legally working individuals who reside temporarily in a country of which they are not a citizen in order to accomplish a career-related goal, being relocated abroad...by an organization'. As such we include many IA variations such as inpatriates and Third Country Nationals.

Whilst we focus on the organizational level of value, given its importance to the GM literature and to the practitioner GM community as noted in numerous consultancy surveys (see, for example Brookfield Global Relocation Services, 2016; Santa Fe Relocation Services, 2019), the framework also incorporates the identification and implications of other levels of value (individual and societal).

This paper makes two primary contributions. First, it provides an extended framework within which researchers can position future studies in order to build a cohesive body of IA literature. This encourages, for example, studies of value capture to consider the relationship with different levels of analysis and studies of value measurement to incorporate the potential levels of complexity. The framework builds on the important work of Lepak et al. (2007) by applying their conceptualization of value to the field of IAs and specifically at the organizational level. In acknowledging the value created by individual assignees for the organizations involved and the societal impact of IAs, this takes a meso level analysis as Lepak et al. (2007) encouraged. Second, we extend Lepak et al.'s (2007) value framework in several ways thereby offering new possibilities for research not solely in the GM field but in other management and IB literatures. We consider the significance of identifying what value is per se and the complexity that this adds. We acknowledge and report on the value implications of intra-organizational sub-levels; the home (sending the assignee), the host (receiving the assignee), other group companies and the group as a whole. We extend the definitions of isolating mechanisms and competition to explicate value capture mechanisms. We also emphasise the importance of temporal analysis in the framework. And finally, we incorporate the issue of value measurement by critiquing and developing extant definitions for assessing 
the organizational value of IAs. By building on existing important work in the ROI IA literature, this latter contribution is of particular importance to the field of GM by offering a stronger basis for future value measurement research and practitioner use.

Our paper first explores the theoretical grounding for organizational value and hence the value creation framework provided by Lepak et al. (2007). We explain the core components of the framework before using it to explicate the value to organizations of international assignments and expatriation. This framework is then extended using and developing the literature to assess the organizational value of IAs demonstrating its value to GM literature. We conclude with a discussion and consideration of the practical implications, the limitations of our approach and the possibilities for further research.

\section{Lepak et al. (2007) and Value Creation}

Lepak et al. (2007) identified the significance of value creation as a central concept in the management and organization literature both at the individual/group (micro) level and the organizational (macro) level, yet they found limited consensus on what value creation is or how it can be achieved. They reported three key reasons for confusion around the issue in the management literature: i) the wide variety of targets or parties for whom value is created, ii) the inconsistency regarding the inclusion of 'what is value' within the definition of value creation (its content in Lepak et al.'s (2007) terminology), and iii) consistent intermingling of value capture or value retention issues when discussing value creation. We begin by positioning the concept of value in the management literature.

Organizational value is not a generally defined academic term. Indeed, many articles use the term 'value' without consideration for its definition (Vandermerwe, 1997; Zhu, Xia and Makino, 2015). Therefore, there is a critical requirement to first explain and operationalize answers to the question, 'what is value?'. As Lepak et al. (2007) noted, the field of organizational strategy offers 
assistance in clarifying the value construct given its focus on achieving long term survival of the firm through value generation and retention (Pitelis, 2009). However, authors have grappled with the definition of value from a strategic perspective (Ambrosini and Bowman, 2009; Pitelis, 2009; Ramírez, 1999). Whilst drawing on other fields of literature, especially economics, they acknowledge that there is no absolute objectivity with respect to the definition of value. Whilst a number (using money as a unit) can be given to indicate value, value is a subjective construct and 'an elusive term in social science and strategic management scholarship' (Pitelis and Teece, 2009), hence the importance of identifying what value is created (the content) before seeking to clarify how it is created. Surprisingly perhaps, whilst Lepak et al. (2007) drew attention to the importance of this distinction and the significance of subjectivity in determining value, they spent limited time considering the value content question and "provide no separate definition of "value" (Pitelis, 2009). This could also explain why they left the question of value assessment or measurement to others - a gap which we address in this paper.

Value creation is the explanation of or the process through which 'value is created from the vantage point or perspective of a particular source' (Lepak, Smith and Taylor, 2007, p.183). Value capture identifies to whom the created value is both accrued and retained. It is determined either by competition or isolating mechanisms generating or preventing 'value slippage' (Lepak, Smith and Taylor, 2007) (see Section 3.3 below for detailed definitions and discussion). This is significant because it is possible to capture value without having first created it (Bowman and Ambrosini, 2000b; Pitelis, 2009). In terms of IAs, the competition element draws attention to the possibility that parties other than the value creator (the organization implementing the IA) affect the level of value accrued or retained. In turn, the isolating mechanisms represent the actions the value creator may take to limit the negative impact of competition on the value created and captured. Whilst we are focused below on the value at the organizational level of analysis, nonetheless, the meso relationships are identifiable as we report on the competitive and isolating mechanisms of the individual assignee and the society within which the IA takes place. 
Lepak et al. (2007) analyzed the multidisciplinary challenges of defining value related issues and noted the scholarly disagreement about the process and construct of value creation especially by organizational scholars. They stressed the contingency nature of value analysis, namely the need to define the source of value, the target users of value and the level of analysis. This contingency perspective illustrates the importance of bringing together value related research in a specific field and hence the importance of using an extended version of the framework for IAs. Lepak et al. (2007) review the implications of different levels of analysis for value - individual, organizational and societal. This research paper extends their framework by explicating the value of IAs specifically at the organizational level, but this requires consideration of the interactions with individual and societal value. We draw attention to the importance of organizational sub-levels: the group (i.e. the combined organization of study), the home (sending people on IA), the host (recipients of assignees), other group entities not involved in the IA, international joint ventures (IJVs) and external organizations. These distinctions are necessary to understand the target users and actual users of the organizational value generated through the use of IAs. External organizations, through the analysis of competitors' impacts on value capture, was explored by Lepak et al. (2007), but intra-organizational questions were left to others and we address this below given its significance to IAs.

Following Lepak et al. (2007) we analyze the organizational value of IAs using a framework of three separate yet related elements - value content, value creation and value capture. We do so through identifying the different subcomponents of the multi-national corporation (MNC) and their roles as target users and actual users of the value created. We focus on MNCs given the extremely limited IA research on other types of organization such as the public sector or charities. 


\section{Applying the Framework to the Organizational Value of IAs}

This section applies each of the components of Lepak et al.'s (2007) framework to the existing knowledge on organizational IA value in order to draw together the disparate elements of research in the IA field, demonstrate the potential linkages between different research streams and provide a stronger basis for future relevant studies. Consistent with Lepak et al.'s (2007) own tabulation method, existing knowledge of IA organizational value is summarized in Table 1. The contents of Table 1 are explained along with appropriate definitions in sections 3.1 to 3.3 below - it is important to acknowledge that given the complex relationships between the elements in the Table, as explained below, it contains only a high-level overview. Nonetheless, this approach allows us to highlight the additions we make to Lepak et al.'s framework, specifically the importance of defining value itself, the different organizational levels and the value assessment dimension. Critically for future studies into the value of IAs, this provides a basis for GM researchers and practitioners to see how their specific topics fit within the broader domain and, therefore, to consider how dynamics between different elements of the framework may affect their research.

\section{INSERT TABLE 1 ABOUT HERE}

\subsection{Value Content}

On examining the literature regarding the organizational value of IAs, we can identify elements of value content (what is value) in line with Lepak et al.'s (2007) framework. However, whilst they acknowledge the complexity created by conflating value content with value creation, they do not define value content. This ignores the complexity as to what is value content, and hence the need to understand this before considering value creation. First it is important to consider the value of IAs from multiple viewpoints. Specifically, at the intraorganizational level of analysis, the value of IAs can be considered from three primary perspectives: the host, the home and the organization as a whole, 
which we refer to as the group (assuming the host and home are in the same group of companies). Other bodies in the intra-organizational network, such as sister subsidiaries and joint ventures, may also be affected through spillover effects. Hence whilst Lepak et al.'s (2007) framework provides the basis for separating the individual, organizational and societal levels of analysis, further attention is required.

The value content to the host (recipient of the international assignee) has been identified in financial terms by various researchers, where the host is a subsidiary of the MNC sending the assignee. This value includes increases in labor productivity, profitability and return on equity (ROE) (Chang, Gong and Peng, 2012; Colakoglu, Tarique and Caligiuri, 2009; Gong, 2003a). The underlying principle of defining value creation through exchange value less use value does not directly apply here because the exchange value of IAs (their cost of implementation) is not analyzed. It is also important to note that whilst academic research may have identified the value of IAs in these ways, practitioners are not actually measuring these relationships (McNulty, De Cieri and Hutchings, 2013).

Whilst there is mainstream support for the financial value created by IAs (Chung and Beamish, 2005; Gong, 2003a; Hyun, Oh and Paik, 2015; Konopaske, Werner and Neupert, 2002; Riaz, Glenn Rowe and Beamish, 2014), the majority of the findings establish that this relationship only exists if certain characteristics are present and the insights regarding these characteristics are highly uncertain (these are reviewed in Section 3 'value capture' below). Furthermore, there are reasons that prevent a confident analysis of published financial figures in relation to the value of IAs to a subsidiary (Geringer and Hebert, 1991). For example, an MNC may enter a country with a loss-making strategy to gain an initial foothold or to acquire market knowledge. Hence the subsidiary's role and relationship with the rest of its group is a significant factor as to its desire for financial gain. Taken together, this supports Lepak et al.'s (2007) approach and the research risks when not acknowledging all aspects of value at the same 
time. As we explore later, this is further complicated by the inter-relationship of value between the individual, organizational and societal parties.

Lepak et al. (2007) identify that the passage of time may affect the value for the parties involved as the context changes. With respect to IAs the value content may vary at distinct points in the process (McNulty and Tharenou, 2004). The financial value to the host organization has been determined both during (Fang et al., 2010; Konopaske, Werner and Neupert, 2002) and after the IA (Chang, Gong and Peng, 2012; Hebert, Very and Beamish, 2005). Whilst conceptual papers draw attention to the intra-organizational effects of IAs on value (see, for example Gaur, Delios and Singh, 2007; Gonzalez and Chakraborty, 2014), no empirical research investigates whether organizational value arises at the same time in the host (subsidiary), the home (parent), the assignee and across the whole organization. In other words, any increase in the value to a host subsidiary might be directly related to the loss in another sister-subsidiary or at the parent (home) generating a net zero outcome. Consider, for example, how the loss of a talented employee sent on IA may destabilise a team at the home and weaken an important client relationship which unexpectedly triggers reduced revenues. This unplanned negative outcome counterbalances the positive effect at the host where the assignee's expertise creates new sales relationships.

It has been shown, for example, that subsidiaries compete against each other for attention and investment from the corporate parent (Bouquet and Birkinshaw, 2008). As conceptualized by Colakoglu, Tarique and Caligiuri (2009) it is feasible that an increase in subsidiary performance due to the arrival of IAs causes a reduction in the performance of other group operations without IAs. This may lead researchers to interpret IAs as having a positive effect, while it might be neutral at the macro level. Similarly, corporate headquarters may suffer in performance as a result of sending its best people overseas to the benefit of local operations. The detrimental effect to the $\mathrm{HQ}$ may be only visible after the IA due to impacts on strategic issues, which need time to take effect. For example, building on the earlier illustration, sending an employee on 
assignment may weaken the home's relationship with a strategically important client yet the impact of this may not be identified until the medium or long term. Again, this extends the significance of temporal and intra-organizational analysis in Lepak et al.'s (2007) framework.

At the micro level of analysis there is evidence that the IA experience of the CEO or executive management triggers value at the group organizational level. This is similar in type to the host value referred to above, e.g. pre-tax ROE, market-to-book ratio and total stock market returns (Carpenter, Sanders and Gregersen, 2001; Daily, Certo and Dalton, 2000). However, this value arises after the IA experience and may be in different organizations (future employers) to those in which the IA occurred, raising considerable doubt as to the total value being generated and the significance of researching value content alongside value creation and value capture over a suitable timeframe.

Value outcomes with less of a direct financial construct have also been identified for IAs, for example capability development, including improved knowledge transfer (KT) and networking capabilities. Internationalization, developing cultural understanding, managing corruption, bringing leadership skills and improved global staffing have also been reported (McNulty, De Cieri and Hutchings, 2009, 2013). The subjective nature of these factors draws further attention to the significance of defining value content prior to assessing value creation given that these benefits are usually excluded in existing IB literature on IA value.

The conclusion to draw here is that Lepak et al.'s (2007) framework benefits from a greater emphasis on the specific identification or definition of value content, acknowledgement of its subjectivity and variability to different organizational constituents and the importance of temporal analysis. The interaction with value capture mechanisms is also a challenge. More importantly this demonstrates the uncertainties and complexities when researching the organizational value of IAs. Without consideration of how value may be defined by the different organizational parties involved one may be ignoring the relationships between them, including the temporal dimensions, and hence 
providing inaccurate definitions and incomplete calculations. We further address the importance of identifying the value content by extending the framework below to incorporate value measurement. First, however, we explicate our understanding of the IA value creation processes.

\subsection{Value Creation Processes}

Whilst it is complicated by conflicting evidence and the value capture boundary conditions (see below) we can identify some important value creation processes for IAs. IA literature has used a wide variety of theoretical perspectives in connection with the issue of value including the resource-based view, the knowledge-based view and the psychological contract. Lepak et al. (2007) identified four streams of literature investigating value creation processes: strategic HRM; innovation; dynamic capabilities; and knowledge generation. The latter two constructs, and especially knowledge transfer (KT), have also been identified as playing an organizational value creation role in IAs (see, for example Dutta and Beamish, 2013; Hebert, Very and Beamish, 2005; Lyles and Salk, 1996).

In line with the different organizational sub-levels involved in IAs, knowledge transferred to the subsidiary, knowledge sustained by the subsidiary and knowledge transferred to the home organization (Gonzalez and Chakraborty, 2014) may all be considered as IA organizational value creation processes. Building on our earlier value content evidence, knowledge transferred to sister companies and external companies may also be a value creation process of IAs. The types of knowledge transferred may include knowledge of trade policies, foreign exchange risks and other cultures (Carpenter, Sanders and Gregersen, 2000). Whilst some research on the KT value creation mechanism had opposite findings, i.e. a lack correlation between KT and subsidiary performance (Colakoglu and Jiang, 2013), the overall theme is clear.

Learning theory and organizational learning is also postulated as an IA value creation process (Dutta and Beamish, 2013; Gong, 2003b): this has a clear link to KT as individuals, teams or organizations learn from assignees' knowledge. Similarly, coordination and control has been used to theorize a value creation 
process in combination with a KT effect (Hyun, Oh and Paik, 2015). Other value creation processes identified in the IA literature with potential interactions with KT include improved communications and consensus building (Carpenter, Sanders and Gregersen, 2000) and intellectual capital (Welch, Steen and Tahvanainen, 2009). Accordingly, this offers consistency with Lepak et al.'s (2007) identification of knowledge generation as a value creation process.

Also consistent with Lepak et al. (2007), the IB literature has suggested dynamic capabilities as having explanatory power when using IAs (Chung and Beamish, 2005). Chung and Beamish (2005) theorized that the ability to transfer the HQ's operational routines to its subsidiaries overseas was a dynamic capability. This can also be interpreted as related to KT. Illustrating the relationships between potential IA value creation processes, Bouquet, Morrison and Birkinshaw (2008) noted that the dynamic capabilities concept supported their hypothesis that organizations benefit from the international attention of their parent company which they offered as a possible organizational value creation process.

International attention of an MNC's senior management is defined as the time and effort they apply to understanding the business' global market place. IA experience was considered to be a key catalyst of this attention as it gives executives a greater ability to interpret complex global events through holding multiple perspectives, tapping into relationship networks and having more sophisticated thought patterns. Hence international attention could be interpreted as a value creation process of IAs, although critically this would be after the IA took place and it may have occurred in a different organization to the one capturing the value, i.e. a future employer. In a similar vein to the key role of senior management's international attention, the IA experience of the CEO has been identified as creating value through the process of being an RBV resource, i.e. one with rarity, inimitability and non-substitutability (Carpenter, Sanders and Gregersen, 2001).

In conclusion, the application of the Lepak et al. (2007) framework within the field of IAs demonstrates that other bodies of literature may offer insights into 
possible value creation processes. Furthermore, the interaction of individual or team level processes on the organizational process of value creation further reinforces the need to apply the framework from a meso perspective - solely investigating one level of value creation analysis without respect for the relationships with other levels leaves the findings open to considerable challenge. This, as further demonstrated below, applies to GM research.

Consistent with Lepak et al.'s (2007) identification that researchers' theoretical perspective has an impact, it is interesting to note that much of the organizational value creation processes identified for IAs is established through hypothesizing a relationship between the use of IAs and organizational performance. Hence the evidence of the very existence of these processes is in most cases open to different interpretations. This suggests that the GM literature would benefit from more investigatory and theoretical work. In contrast, there is considerable evidence regarding the mechanisms that affect IA value capture as these have been interrogated as mediators. We now turn to consider these issues.

\subsection{Value Capture Mechanisms}

Value capture has two critical aspects: 'Who captures the value?' including their characteristics and 'How is value captured?' which considers process mechanics and negotiating positions such as those within supply chain analysis (Lepak, Smith and Taylor, 2007). As identified above, the intra-organizational value derived from IAs could be at the home, the host or other group organizations and there is a complex relationship between these parties (Dickmann and Doherty, 2010; McNulty, 2013). Lepak et al.'s (2007) framework provides two key concepts operating across all levels of analysis which determine who captures the value: isolating mechanisms and competition. We extend the definitions offered by Lepak et al. (2007) in each case to apply these to IAs; extensions which may also offer benefit to other fields of study.

First, an isolating mechanism is defined by Lepak et al. as 'any knowledge, physical, or legal barrier that may prevent replication of the value-creating new task, product, or service by a competitor' (2007, p.188). We suggest that a 
company cannot prevent the use (replication) of IAs by a competitor company, given separate legal arrangements. However, government intervention can create barriers to the use of IAs for example in raising taxes or limiting visas. It is difficult to see how this might target individual MNCs although certain MNCs might react differently to others to the same barriers. On the other hand, such interventions may enable society to share in (compete for) the value created by charging high visa fees or other taxes. Accordingly, the definition of isolating mechanisms needs to be extended to include the characteristics of organizations, which reduce the ability of others to share in the value created through the use of IAs.

Secondly, Lepak et al.'s (2007) approach to competition focuses on marketplace competition to supply similar products or services causing a reduction in the sales price (or exchange value) and hence a value retention opportunity for the original product or service provider (the value creator). Such a concept is not directly relevant to IAs and hence we introduce an alternative perspective that other parties may take value away from the value creating organization, such as the individual assignee or society through demanding salary increases or charging taxes. We start here by explicating the isolating mechanisms for IAs.

Subsidiaries with more international customers benefit more from implementing IAs than those with fewer such customers (Richards, 2001) hence the creation of such a customer base may act as an isolating mechanism in the value generated through the use of IAs. Building on this, the international approach of a company using IAs, in relation to its global mindset (Oddou, Osland and Blakeney, 2009) or global strategic posture (Carpenter, Sanders and Gregersen, 2001) is an important isolating factor. In so far as MNCs can establish their operational style and culture as a strategic decision, having such an international approach is seen as increasing the level of value achieved through employing CEOs or senior managers with IA experience. However, as already noted above, this IA experience may have taken place at a different organization which complicates the interpretation of this isolating factor as it 
may be enabling a competitor to retain value rather than the IA value creator. This implies that the original employer needs to offer greater incentives if they wish to retain their IA-experienced employee.

A range of HRM practices may operate as isolating mechanisms on an organization's ability to capture IA value. Primary examples are their repatriation and retention capabilities (McNulty and De Cieri, 2011; Yan, Zhu and Hall, 2002). In a direct link to the importance of KT as a value creation process, Oddou et al.'s (2009) conceptual paper strongly emphasizes the value of assignee retention to deliver KT to the home organization. There is an intriguing relationship between the impact of effective repatriation and retention processes combined with the international approach of the organization. If there is a lack of international approach then the retention may actually have limited effect on capturing value. This raises the question as to whether effective employee repatriation and retention is necessarily a value capturing mechanism and that the value content for an organization may be maximized without assuming effective repatriation.

The operational needs of the host organization (Tan and Mahoney, 2006) or the nature of the role of a subsidiary within its MNC network, such as standalone versus highly integrated (Colakoglu, Tarique and Caligiuri, 2009), may operate as forms of isolating mechanisms. Again, this is closely linked to value creation through KT. For example, if the host has limited need for the technical excellence of an assignee then the assignee is unlikely to be able to create value nor find a scenario in which knowledge and hence value retention is likely. Tan and Mahoney (2006) identified that higher local product customization needs, lower local experience and lower local advertising intensity each correlate with greater IA use and hence indicate situations when greater value may be captured by the host. Building on these ideas of information usefulness, both host absorptive capacity (Chang, Gong and Peng, 2012; Lyles and Salk, 1996) and home absorptive capacity post repatriation (Oddou, Osland and Blakeney, 2009) would seem to be isolating mechanisms for IA value capture. This draws attention to the relationship between home and host as competing 
parties for value capture. For example, a longer assignment period at the host might increase value capture for the host to the detriment of the home. Indeed, given the increasing identification of globe-trotting nomads, i.e. those assignees that rotate through IAs rather than return home (Forster, 2000), this raises further uncertainties as to the nature of organizational value capture.

These examples for IAs illustrate the need to expand the Lepak et al. (2007) definition of isolating mechanisms to understand the value capture dynamics in addition to the importance of temporal analysis. For the field of IAs it demonstrates the numerous and complex interactions between isolating mechanisms and hence the difficulty and importance of addressing these within IA value research. We now turn to the question of competition sharing in the value created by the IA implementing organization. We use the three different levels of analysis identified by Lepak et al. (2007) to organize our analysis: the individual/group; the organization; and society, starting with the organization. This draws attention to the challenges in focusing only on one level of value for IA research and the potential difficulties of isolating value at these different levels.

\subsubsection{Organizational Competition}

We have already identified the possibility that different entities within an intraorganizational structure may be competing, inadvertently or otherwise, for the value created by an IA. If an individual is sent on an IA as a leadership development experience then a sister organization, whether in the same country as the host or elsewhere, could seek to recruit the individual and hence benefit from the value the assignee might create. The funding of an IA does not automatically sit with the organization in which the assignee works whilst on assignment (Renshaw, Parry and Dickmann, 2018a) which further complicates this dynamic. Similarly, competition for the value generated by IAs is present when other organizations seek to employ/poach staff. As an example, Daily et al. (2000) found that the positive relationship between CEO IA experience and firm performance was moderated by outside succession. Given the growing identification of global talent shortages (Baruch, Altman and Tung, 2016), this 
poaching is a credible risk which is reinforced by the oft-repeated finding that large numbers of assignees suffer poor repatriation processes and leave their organizations within a short time of the said repatriation (Baruch, Altman and Tung, 2016). Of course, this may be exacerbated if the home organization does not have the appropriate level of international approach as discussed earlier.

\subsubsection{Individual Competition}

Individual competition relates to two aspects: the assignee and the individuals the assignee works with. There is a known interaction between the value to an assignee's career and value to the organization (Dickmann and Doherty, 2010; Doherty and Dickmann, 2009; Welch, Steen and Tahvanainen, 2009). Hence, the assignees themselves may capture some of the organizational value, reducing what is captured by the original or future employer. Carpenter et al. (2001) found that CEOs with IA experience obtained higher pay than those without IA experience provided the firm had a greater global strategic posture. This finding is consistent with the hypothetical example in which employees negotiate for some of the value they create as provided by Lepak et al. (2007, p.188) and could be a function of negotiating capabilities and/or market demand and supply characteristics. The competition for value capture is also present in the alignment of the assignee's goals with the organization's goals whilst on IA (Yan, Zhu and Hall, 2002). As a result, effective management of the psychological contract could operate as an isolating factor limiting this loss of value to the assignee (McNulty, De Cieri and Hutchings, 2013).

Value may also be captured by the individuals that an assignee works with, for example through the effect of knowledge transfer or leadership development of staff members. This may then create a secondary value creation effect through which those colleagues are now able to generate greater value for the employer and hence also negotiate higher salaries. They may even leave the organization to work for a competitor. Hence the organizational value of IAs to an employer is a function of their value to the individual assignee as well as to other employers poaching their staff. 


\subsubsection{Societal Competition}

Changes in the society in which IAs are operating can impact upon the value derived by the host organization. For example taxation on employers or on consumption by the assignee and their families may affect this value (Dustmann, Frattini and Halls, 2010). The latter may cause assignees to seek a greater share of the value they create for the organization. Society may also be affected through the cultural and work integration and environmental impact of the assignee, their family and the organization for whom they work (Al Ariss and Syed, 2011; Hippler, Caligiuri and Johnson, 2014). Imagine scenarios in which society becomes more open and encourages greater integration of expatriates. This may generate unexpected reputational or brand value to the employers. The value created by IAs may extend beyond the organization itself into the wider context in a way that may be competitive but also complementary. For example, assignee adjustment is an important element of IA research given its relationship with time to proficiency, i.e. the point at which an assignee is effective in their new role (Selmer and Lauring, 2016). And as the adjustment of an assignee increases enabling positive societal change through their cultural interactions (Takeuchi, 2010) so they have greater potential value to their employer. This raises the question of whether organizations should consider societal value as having concomitant indirect value to the organization, e.g. by enhancing its employer brand. All these factors, especially those beyond the direct influence of the employer, demonstrate how IA organizational value is partly a function of societal value.

In concluding this section, we note the importance of considering the individual and societal level of isolating mechanisms and competition when explicating the organizational level. This reinforces Lepak et al.'s (2007) recommendation that their framework be considered from a meso perspective. Furthermore, the importance of considering the intra-organizational, intra-individual and conceptually the intra-societal levels of analysis combined with the temporal approach is also clear. 


\section{Extending the Value Framework: Value Assessment}

\subsection{Complications and Existing Definitions}

In understanding the value creation and value capture dynamics we have emphasized the importance of identifying the value which is being created and/or captured. Hence, we argue, there is a need to determine a methodology to identify these value outcomes. As practitioners continue to decry their lack of measurement capability (Santa Fe Relocation Services, 2019) we believe there is limited benefit in extending our theoretical understanding of value content, creation and capture unless we can bring these issues together. Similarly, we believe that measurement techniques will create an iterative benefit in enabling greater clarity on value content, creation and capture. Establishing value assessment processes enables the operationalization of each aspect of value an issue that Lepak et al. (2007) did not address. Nonetheless, as evidenced below, we do not suggest that this measurement is an easy task.

At the organizational level, the assessment of IA value is rare (McNulty, 2008; Schmidt and Minssen, 2007). The barriers to assessing organizational value are operational (e.g. unavailable data), cultural (e.g. the perception that IAs are a necessity of doing business such that valuation is not required) and strategic (e.g. a lack of ownership of the issue) (McNulty, De Cieri and Hutchings, 2009). Whilst several enabling conceptual frameworks exist for the measurement of the IA organizational level of value, it is clear that at a practical level there are many interacting variables involved in the measurement process (Hemmasi, Downes and Varner, 2010; Schiuma, Bourne and Harris, 2006; Yan, Zhu and Hall, 2002). Acknowledging the different organizational and individual goals and their inter-relationships, a range of different calculations and data are appropriate in order to manage and measure IA value. It is noticeable, however, that the extant measurement frameworks treat the organization implementing the IA as a single entity and do not separate the home, the host, or other organizational entities as having potentially distinct value content, value creation, value capture and hence value assessment outcomes. This creates an important contribution to IA research. 
There are two definitions offered in extant IA literature seeking to provide a theoretical and practical over-riding construct of value for IAs and both use the term ROI (Return on Investment). The first definition of IA ROI was offered by McNulty and Tharenou: 'a calculation in which the financial and nonfinancial benefits to the MNC are compared with the financial and nonfinancial costs of the international assignment, as appropriate to the assignment's purpose.' (2004, p.73). While this definition has made an important contribution to the field, it disregards the sub-levels of the MNC and raises questions as to what 'appropriate' means. McNulty \& De Cieri provide a formulaic definition of 'Expatriate ROI': eROI = cROI + iROI (2016, p9). This implies that total IA ROI is a function of two additive and separate elements: cROI (the organizational value to the corporate) and iROI (the value to the individual) even though the text itself indicates a broader approach. Yan et al. (2002) argue that the alignment between the assignee and the organization(s) is crucial to predicting and achieving success (i.e. value) and Hemmasi et al.'s (2010) multidimensional measures of success illustrate how the factors affecting organization and individual assignee are intertwined. This fits with i) Lepak et al.'s (2007) insistence that value dynamics need to be understood in terms of the level of analysis, ii) the concept that competition between parties may affect the total level of value created and iii) our findings which demonstrate the impact of the different sub-components of the organizational level of analysis. The additive nature of the above formula and its exclusion of societal level value does not cater to the theoretical and empirical evidence regarding the intrarelationship between the component parts that we have identified above.

Drawing on these issues we now offer some initial thoughts to extend the theoretical formulations for assessing the organizational value of IAs and hence Lepak et al.'s (2007) value creation framework.

\subsection{New Definitions of Value Assessment - Extending Theory and Supporting Practitioners}

Separating value content, value creation and value capture is commensurate with assessing value at three different points in time and consistent with the IA 
pre-departure phase, the time during assignment and the time after the assignment (Sparrow, Brewster and Harris, 2004). For practitioners this enables judgment on whether an IA investment should go ahead, whether the investment is performing as anticipated and whether the investment performed compared to expectations. The latter two calculations provide valuable insight for future decision-making by HR functions. Emphasizing the implications of the timeliness of calculations, and hence the differences in value creation and capture over time, is a key extension to Lepak et al.'s (2007) framework.

Whilst McNulty and Tharenou's (2004) paper identifies the importance of taking the long-term perspective and issues of timing when assessing ROI, their definition of $\mathrm{ROI}$ is potentially limited to the pre-departure value calculation because it is restricted to costs and benefits 'as appropriate to the assignment's purpose' (2004, p.73). A pre-departure value assessment considers expected or anticipated events yet these may be 'inappropriate' to that perceived at the outset. Value calculations during or after the IA need to include the costs and benefits that have unexpectedly or 'inappropriately' arisen. Furthermore, allowance for the unexpected is required considering, for example, if experience shows that unexpected costs or benefits regularly arise. Excluding these, both in theory and practice, would be illogical if they represent 'known unknowns'.

In addition, indirect costs and benefits, i.e. those that cannot be or are not in practice directly attributable to the IA, should be included in value assessments (Nowak and Linder, 2016). Indirect costs might be those of the legal and administrative teams providing support to the IA process (Doherty and Dickmann, 2012) and indirect benefits might be increased sales revenues as a result of improved leadership. As acknowledged in the financial literature, the practical allocation of indirect costs may not be straight forward and different methods exist, nonetheless it is a vital part of any financial calculation given that the identification and allocation of direct and indirect costs (and revenues) is itself a complex and subjective decision (Ionescu et al., 2019). Finally, the uncertain nature of the calculations draws attention to the need to alter them for the time-value-of-money (TVM) (Nowak and Linder, 2016) using an 
appropriately adjusted discount factor. In practice, HR functions will need to align this with their organization's approach to risk calculations. HR practitioners should also consider the different sub-levels of the organization which may be affected in each calculation. In conclusion, consistent with our recommendations that temporal elements are appropriate to the Lepak et al. (2007) framework in its entirety, calculations of value during and after the assignments need to differ to the pre-departure version:

- Pre-departure definition of IA organizational value content: a calculation for a planned IA in which the anticipated direct and indirect financial and non-financial benefits to a part or all of an organization are compared with the anticipated direct and indirect financial and nonfinancial costs to that part of the organization. All numbers are adjusted for the time-value-of-money.

- Post departure definition of IA organizational value content: a calculation regarding an ongoing or completed IA in which the actual and still anticipated direct and indirect financial and non-financial benefits to a part or all of the organization are compared with the actual and still anticipated direct and indirect financial and non-financial costs to that part of the organization. All numbers are adjusted for the time-value-ofmoney.

Whilst we acknowledge that extending the definitions in this way does not make them any easier to calculate in practice, it does provide practitioners with clarity on what to aim for and opens up the discussion as to the potential subjectivity of some of the relevant components. Importantly we also propose that the Lepak et al. (2007) framework can be extended by applying these same definitions to other human resource and broader management interventions.

The McNulty and De Cieri (2016, p9) definition of ROI ('Expatriate ROl': eROI = $\mathrm{CROI}+\mathrm{iROI}$ ) can also be refined using the findings of this paper presenting an alternative formulaic approach. Distinct organizational components of value capture for an IA have been identified with the host, the home and other group organizations being affected. Organizational value can be captured by the 
assignee and, by extrapolation it is possible that other employees may also be affected. In keeping with Lepak et al.'s (2007) identification that value may vary at individual, organization and societal levels, society also needs to be considered in any value formula. Finally, it has been shown that value may be taken by a future employer of the assignee. In summary, total IA organizational value is a function of that gained by each of the individual (I), other employees $(E)$, the host $(S)$, the home $(M)$, other group entities $(G)$, society (Soc) and future employers of the assignee (FE).

The value captured by each of these elements is a function of the value captured by the other elements and by the passage of time and hence the time value of money (TVM). The idea of risk has been incorporated into growing levels of IA research which assess the different phenomena in high risk politically unstable or war affected host locations (see, for example Bader, Schuster and Dickmann, 2019; Soltani and Wilkinson, 2011). In the same vein the formula for organizational value should take a risk-based view in determining the appropriate discount factor with which to assess the TVM. The pre-departure IA organizational value would be different ceteris paribus, between an IA to a stable nearby geographic location as compared to a far-off unstable war zone. The fact that organizational value of IAs is a function of these different factors can be represented as:

Total Organizational Value $=f($ value $(\mathrm{I}, \mathrm{E}, \mathrm{S}, \mathrm{M}, \mathrm{G}, \mathrm{FE}$, Soc,time,risk $))$

On the basis of the above we propose an application and extension of the Lepak et al. (2007) framework from which to compare and contrast future research into the value of activities at the organizational level (see Figure 1), including IAs. The starting point remains the identification and definition of the value content, along with the value creation and value capture mechanisms. The target users of value at the organizational sub-levels need to be identified along with the societal, organizational and individual users which, in combination with the dynamics of value assessment before, during and after an intervention, are crucial for moving forward our understanding of the value of 
interventions (including IAs) and hence enabling HR functions to manage them more effectively. We believe that the new definitions and formula we offer above can be adapted and applied to other contexts and hence the Lepak et al. (2007) framework can be extended to incorporate value assessment. As we identified earlier, the variability of value content in different scenarios illustrates the importance of such an assessment component in the framework.

\section{INSERT FIGURE 1 ABOUT HERE}

\section{Discussion}

Enhancing our understanding of the organizational value of IAs has been identified as an important research need (Baruch, Altman and Tung, 2016; Bonache and Zárraga-Oberty, 2017). To date IA research has tended to focus on one perspective of this issue with limited acknowledgment of the broader complexities when studying questions of organizational value. Findings that report gains to subsidiary hosts of assignees without due recognition that the home may have lost value at the same time is a particularly significant example in extant research. We have provided and extended an influential paper on value by Lepak et al. (2007) to offer the GM and IB communities a new framework within which future research may sit in order to build a newly cohesive whole.

Lepak et al.'s (2007) article has had an important impact on the understanding of value creation in the management and international business literature. Following their recommendations, we have applied their value creation and capture framework taking a meso level approach to the specific case of IAs. As a result we have reinforced the usefulness of their approach and identified several extensions to further improve this usefulness. Our case develops the framework for the field of IAs in several ways whilst maintaining and extending its impact across the management research field.

Defining or identifying the value content in order to understand the creation processes in the IA field and elsewhere should not be overlooked. Value content can be identified and described in a wide range of terms from financial 
to non-financial and with considerable subjectivity. The type of value may differ depending upon the specific party affected in an organizational network where, for example, a subsidiary recipient of IAs may have a different local perspective to that of its parent or other subsidiaries. As Lepak et al. (2007) noted, identifying the target users of any value created is crucial to understanding the full picture. Furthermore, separate entities in an organizational network using IAs may be competing against each other to maximize their own value retention (Renshaw, Parry and Dickmann, 2018b). Whilst we did not consider this due to our focus at the organizational level of analysis, the individual's interpretation of value in the case of IAs may also differ to that of the overall organization itself (McNulty, De Cieri and Hutchings, 2013).

Temporal analysis is fundamental to the value framework. Expectations of value before an intervention may differ to findings both during and after the intervention. Describing value creation in terms of exchange value less use value may be an over-simplification, as impacts on value may arise a considerable time after the specific intervention. Whilst, for example, an IA may generate greater productivity for a host subsidiary whilst it lasts (Riaz, Glenn Rowe and Beamish, 2014), the cost impacts on the home organization in relation to attrition may not arise until much later. Similarly, the impact on the assignee's productivity and impact may last until they achieve the CEO spot or retirement - each of which may be in a different organization (Carpenter, Sanders and Gregersen, 2001). The relationship between identifying the target users of the value and the timeframes within which value may be both created and captured is key to understanding organizational value.

An understanding of the role of isolating mechanisms and competition is needed to explicate organizational value capture in IA usage as well as elsewhere. However, the definitions offered by Lepak et al. (2007) needed refining to recognize that competition is not solely a market-based organizational construct and depends upon relationships between different levels of analysis, i.e. individual, organizational and societal. For example, individuals and societies are involved in competing for the value created by IAs 
in organizations and each may have their own isolating mechanisms and competitive structures. As we have shown specifically for IA research, this needs further consideration given the intra-level relationships involved.

Explicating value creation and value capture involves an understanding of the levels of value involved, which necessitates a value assessment mechanism - a crucial issue for GM practitioners. Extending Lepak et al.'s (2007) analysis and building on the IA context we offer new definitions for value assessment refining the work of other scholars. A descriptive and a formulaic approach are offered. Whilst these are explicated specifically for IA value purposes, we believe these can be adjusted and applied to other management interventions. These calculations in practice are potentially complex and, at least in the IA case, represent a stretch for practitioners who are mostly not measuring the value of these interventions currently (McNulty, De Cieri and Hutchings, 2013; Santa Fe Relocation Services, 2019). Nonetheless these definitions provide an important starting point given that these complexities need to be understood in order not to accidentally exclude elements of value in the measurement process.

From a practitioner perspective our paper highlights the importance of understanding all of the different aspects of the organizational value framework (Figure 1). Practitioners express the desire to identify the value their IAs generate. Our framework allows them to identify that a comprehensive and impactful response to this issue requires a review of how they might define the value they wish to create, how they think value will be created, how and by whom they think it will be captured and hence how they might measure this value. There is an iterative relationship between these factors. And within this our paper draws their attention to the complexities in each of these issues, for example the subjectivity involved, the different organizational parties potentially involved and the interconnectivity, for example how some value captured by the individual assignee may be equally beneficial to the employer (decision-making capability) whereas other value may not be (increased pay). Hence practitioners have greater insight with which they might determine the value of individual IA opportunities more effectively in addition to their overall global mobility 
strategies. We have set out a roadmap whilst acknowledging the potholes and crossroads involved.

\section{Conclusions, Limitations and Opportunities for Further Research}

Noting the increasing citations and hence importance of Lepak et al.'s (2007) paper on value creation and value capture, this paper offers a useful framework within which to coalesce the complexities affecting the GM literature and its study of the organizational value of IAs.

In addition to applying this framework to the specifics of organizational value creation and capture through the use of IAs, our contribution is the extension of the framework itself. We do so through i) emphasizing the importance of defining and identifying the value content itself, ii) through incorporating temporal analysis and intra-organizational analysis, iii) by extending the definitions of isolating mechanisms and competition to explicate value capture, and finally, iv) by adding organizational value assessment with appropriate definitions built upon important prior IA research.

Whilst we offer immediate value to the field of GM through our extended framework there are some limitations. Further research within different contexts and to different phenomena might extend our understanding and further explicate the subtleties of the extended framework. Similarly, taking a specific theoretical or philosophical perspective on value may further add to our understanding given the many different potential approaches, including those taken from other bodies of literature. And finally, using the framework to focus on the societal or individual level of value will also be insightful elsewhere. This, we suggest, will require a similarly in-depth critique of existing literature.

For GM research we have drawn on a wide range of IA studies providing a detailed analysis of an important issue to global businesses in which the uncertainty surrounding its value remains fundamental. Our framework demonstrates the challenges and relationships that require consideration when 
researching this important issue. This should enable future IA research to identify where it fits in relation to other studies, the complexities arising within different levels of analysis and the connections to the broader field of understanding value. 


\section{References}

Ambrosini, V. and Bowman, C. (2009) 'What are dynamic capabilities and are they a useful construct in strategic management?', International Journal of Management Reviews, 11(1), pp. 29-49.

Al Ariss, A. and Syed, J. (2011) 'Capital mobilization of skilled migrants: A relational perspective', British Journal of Management, 22(2), pp. 286-304.

Bader, B., Schuster, T. and Dickmann, M. (2019) 'Managing People in Hostile Environments: Lessons Learned and New Grounds in HR Research', The International Journal of Human Resource Management Special Issue on Hostile Environments., 30(20), pp. 2809-2830.

Baruch, Y., Altman, Y. and Tung, R.L. (2016) 'Career Mobility in a Global Era: Advances in Managing Expatriation and Repatriation', The Academy of Management Annals, 10(1), pp. 841-889.

Bonache, J. and Zárraga-Oberty, C. (2017) 'The traditional approach to compensating global mobility: criticisms and alternatives', The International Journal of Human Resource Management, 28(1), pp. 149-169.

Bouquet, C. and Birkinshaw, J. (2008) 'Weight versus voice: How foreign subsidiaries gain attention from corporate headquarters', Academy of Management Journal, 51(3), pp. 577-601.

Bouquet, C., Morrison, A.J. and Birkinshaw, J. (2008) 'International attention and multinational enterprise performance', Journal of International Business Studies, 40(1), pp. 108-131.

Bowman, C. and Ambrosini, V. (2000a) 'Value Creation Versus Value Capture: Towards a Coherent Definition of Value in Strategy', British Journal of Management, 11(1), pp. 1-15.

Bowman, C. and Ambrosini, V. (2000b) Value creation versus value capture: towards a coherent definition of value in strategy - an exploratory study.

Brookfield Global Relocation Services (2016) 2016 Global Mobility Trends Survey: Breakthrough to the Future of Global Talent Mobility. Morristown, New Jersey. 
Carpenter, M.A., Sanders, W.G. and Gregersen, H.B. (2001) 'Bundling Human Capital With Organizational Context: the Impact of International Assignment Experience on Multinational Firm Performance and CEO Pay', Academy of Management Journal, 44(3), pp. 493-511.

Carpenter, M.A., Sanders, W.G. and Gregersen, H.B. (2000) 'International assignment experience at the top can make a bottom-line difference', Human Resource Management, 39(2-3), pp. 277-285.

Chang, Y.-Y., Gong, Y. and Peng, M.W. (2012) 'Expatriate Knowledge Transfer, Subsidiary Absorptive Capacity, and Subsidiary Performance', Academy of Management Journal, 55(4), pp. 927-948.

Chung, C.C. and Beamish, P.W. (2005) 'Investment mode strategy and expatriate strategy during times of economic crisis', Journal of International Management, 11(3), pp. 331-355.

Colakoglu, S. and Jiang, Y. (2013) 'Subsidiary-level outcomes of expatriate staffing: an empirical examination of MNC subsidiaries in the USA', European J. of International Management, 7(6), pp. 696-718.

Colakoglu, S., Tarique, I. and Caligiuri, P.M. (2009) 'Towards a conceptual framework for the relationship between subsidiary staffing strategy and subsidiary performance', The International Journal of Human Resource Management, 20(6), pp. 1291-1308.

Collings, D.G., Mellahi, K. and Cascio, W. (2019) 'Global talent management and performance in multinational enterprises: a multilevel perspective', Journal of Management, 45(2), pp. 540-566.

Collins, C.J. (2020) 'Expanding the resource based view model of strategic human resource management', International Journal of Human Resource Management, Online

Daily, C.M., Certo, S.T. and Dalton, D.R. (2000) 'International experience in the executive suite: the path to prosperity?', Strategic Management Journal, 21(4), pp. $515-523$.

Dickmann, M. and Doherty, N.T. (2010) 'Exploring organizational and individual 
career goals, interactions, and outcomes of developmental international assignments', Thunderbird International Business Review, 52(4), pp. 313-324.

Doherty, N.T. and Dickmann, M. (2009) 'Exposing the symbolic capital of international assignments', The International Journal of Human Resource Management, 20(2), pp. 301-320.

Doherty, N.T. and Dickmann, M. (2012) 'Measuring the return on investment in international assignments: an action research approach', The International Journal of Human Resource Management, 23(16), pp. 3434-3454.

Dustmann, C., Frattini, T. and Halls, C. (2010) 'Assessing the Fiscal Costs and Benefits of A8 Migration to the UK', Fiscal Studies, 31(1), pp. 1-41.

Dutta, D.K. and Beamish, P.W. (2013) 'Expatriate Managers, Product Relatedness, and IJV Performance: A Resource and Knowledge-based Perspective', Journal of International Management, 19(2), pp. 152-162.

Edström, A. and Galbraith, J.R. (1977) 'Transfer of managers as a coordination and control strategy in multinational organizations', Administrative Science Quarterly, 22(2), pp. 248-263.

Fang, Y., Jiang, G.L.F., Makino, S. and Beamish, P.W. (2010) 'Multinational firm knowledge, use of expatriates, and foreign subsidiary performance', Journal of Management Studies, 47(1), pp. 27-54.

Forster, N. (2000) 'The myth of the "international manager"', The International Journal of Human Resource Management, 11(1), pp. 126-142.

Gaur, A.S., Delios, A. and Singh, K. (2007) 'Institutional Environments, Staffing Strategies, and Subsidiary Performance.', Journal of Management, 33(4), pp. 611636.

Geringer, J.M. and Hebert, L. (1989) 'Control and performance of international joint ventures', Journal of International Business Studies, 20(2), pp. 235-254.

Geringer, J.M. and Hebert, L. (1991) 'Measuring Performance of International Joint Ventures', Journal of International Business Studies, 22(2), pp. 249-263.

Gong, Y. (2003a) 'Subsidiary Staffing in Multinational Enterprises: Agency, 
Resources, and Performance', Academy of Management Journal, 46(6), pp. 728739.

Gong, Y. (2003b) 'Toward a dynamic process model of staffing composition and subsidiary outcomes in multinational enterprises', Journal of Management, 29(2), pp. 259-280.

Gonzalez, J.A. and Chakraborty, S. (2014) 'Expatriate knowledge utilization and MNE performance: A multilevel framework', Human Resource Management Review, 24(4), pp. 299-312.

Hebert, L., Very, P. and Beamish, P.W. (2005) 'Expatriation as a Bridge Over Troubled Water: A Knowledge-Based Perspective Applied to Cross-Border Acquisitions', Organization Studies, 26(10), pp. 1455-1476.

Hemmasi, M., Downes, M. and Varner, I.I. (2010) 'An empirically-derived multidimensional measure of expatriate success: reconciling the discord', The International Journal of Human Resource Management, 21(7), pp. 982-998.

Hippler, T., Caligiuri, P.M. and Johnson, J. (2014) 'Revisiting the Construct of Expatriate Adjustment', International Studies of Management and Organization, 44(3), pp. 8-24.

Hyun, H.-J., Oh, C.H. and Paik, Y. (2015) 'Impact of nationality composition in foreign subsidiary on its performance: a case of Korean companies', The International Journal of Human Resource Management, 26(6), pp. 806-830.

lonescu, O., Bhimani, A., Datar, S., Horngren, C. and Rajan, M. (2019) Management and Cost Accounting. Pearson.

Jia, X. (2020) 'Corporate social responsibility activities and firm performance: The moderating role of strategic emphasis and industry competition', Corporate Social Responsibility and Environmental Management, 27(1), pp. 65-73.

Konopaske, R., Werner, S. and Neupert, K.E. (2002) 'Entry mode strategy and performance: The role of FDI staffing', Journal of Business Research, 55(9), pp. 759-770.

Lepak, D.P., Smith, K.G. and Taylor, M.S. (2007) 'Value Creation and Value 
Capture: A Multilevel Perspective', Academy of Management Review, 32(1), pp. 180-194.

Lyles, M.A. and Salk, J.E. (1996) 'Knowledge acquisition from foreign parents in international joint ventures: an empirical examination in the Hungarian Context', Journal of Intellectual Capital, 27(5), pp. 877-903.

McNulty, Y.M. (2013) What Not To Do When Measuring Expatriate ROI, InternationalHRAdviser, , pp. 3-5.

McNulty, Y.M. (2008) 'How a major multinational is working to overcome the barriers to improved expatriate ROl', Global Business and Organizational Excellence, 27(3), pp. 38-47.

McNulty, Y.M. and Brewster, C. (2017) 'Theorizing the meaning(s) of "expatriate": establishing boundary conditions for business expatriates', The International Journal of Human Resource Management, 28(1), pp. 27-61.

McNulty, Y.M. and De Cieri, H. (2016) 'Linking global mobility and global talent management: the role of ROI', Employee Relations, 38(1), pp. 8-30.

McNulty, Y.M. and De Cieri, H. (2011) 'A Critical Review of Approaches to Measuring Expatriate Return on Investment', Australia and New Zealand Academy of International Business (ANZIBA) Conference. Melbourne, Australia, pp. 1-27.

McNulty, Y.M., De Cieri, H. and Hutchings, K. (2013) 'Expatriate return on investment in the Asia Pacific: An empirical study of individual ROI versus corporate ROI', Journal of World Business, 48(2), pp. 209-221.

McNulty, Y.M., De Cieri, H. and Hutchings, K. (2009) 'Do global firms measure expatriate return on investment? An empirical examination of measures, barriers and variables influencing global staffing practices', The International Journal of Human Resource Management, 20(6), pp. 1309-1326.

McNulty, Y.M. and Tharenou, P. (2004) 'Expatriate Return on Investment: A definition and antecedents', International Studies of Management and Organization, 34(3), pp. 68-95.

Nair, S. and Blomquist, T. (2020) 'The temporal dimensions of business incubation: 
A value-creation perspective', International Journal of Entrepreneurship and Innovation, 21(1), pp. 38-46.

Nowak, C. and Linder, C. (2016) 'Do you know how much your expatriate costs? An activity-based cost analysis of expatriation', Journal of Global Mobility, 4(1), pp. 88107.

Oddou, G., Osland, J.S. and Blakeney, R.N. (2009) 'Repatriating knowledge: variables influencing the "transfer" process', Journal of International Business Studies, 40(2), pp. 181-199.

Olk, P. and West, J. (2020) 'The relationship of industry structure to open innovation: cooperative value creation in pharmaceutical consortia', R\&D Management, 50(1. Special Edition), pp. 116-135.

Pitelis, C.N. (2009) 'The Co-Evolution of Organizational Value Capture, Value Creation and Sustainable Advantage', Organization Studies, 30(10), pp. 1115-1139.

Pitelis, C.N. and Teece, D.J. (2009) 'The (new) nature and essence of the firm', European Management Review, 6(1), pp. 5-15.

Ramírez, R. (1999) 'Value co-production: Intellectual origins and implications for practice and research', Strategic Management Journal, 20(1), pp. 49-65.

Renshaw, P.S.J., Parry, E. and Dickmann, M. (2018a) 'Seconded National Experts and global mobility - Extending the paradigm', Thunderbird International Business Review, 60(6), pp. 897-909.

Renshaw, P.S.J., Parry, E. and Dickmann, M. (2018b) 'The Value of International Assignments as Microfoundations of Dynamic Capabilities', EURAM Conference Proceedings (Reykjavik)., pp. 1-39.

Riaz, S., Glenn Rowe, W. and Beamish, P.W. (2014) 'Expatriate-deployment levels and subsidiary growth: A temporal analysis', Journal of World Business, 49(1), pp. $1-11$.

Richards, M. (2001) 'U.S. multinational staffing practices and implications for subsidiary performance in the U.K. and Thailand', Thunderbird International Business Review, 43(2), pp. 225-242. 
Santa Fe Relocation Services (2019) ReVision. Mobility through the looking glass.

Schiuma, G., Bourne, M. and Harris, H. (2006) 'Assessing the value of international assignments', Measuring Business Excellence, 10(1), pp. 60-71.

Schmidt, S. and Minssen, H. (2007) 'Accounting for international assignments: the case of the German chemical industry', Journal of Human Resource Costing \& Accounting, 11(3), pp. 214-228.

Selmer, J. and Lauring, J. (2016) 'Work engagement and intercultural adjustment', International Journal of Cross Cultural Management, 16(1), pp. 33-51.

Soltani, E. and Wilkinson, A. (2011) 'The Razor's edge: Managing MNC affiliates in Iran', Journal of World Business, 46(4), pp. 462-475.

Sparrow, P.R., Brewster, C. and Harris, H. (2004) Globalizing Human Resource Management. London: Routledge.

Takeuchi, R. (2010) 'A Critical Review of Expatriate Adjustment Research Through a Multiple Stakeholder View: Progress, Emerging Trends, and Prospects', Journal of Management, 36(4), pp. 1040-1064.

Tan, D. and Mahoney, J.T. (2006) 'Why a multinational firm chooses expatriates: Integrating resource-based, agency and transaction costs perspectives', Journal of Management Studies, 43(3), pp. 457-484.

Vandermerwe, S. (1997) 'Increasing returns: Competing for customers in the global market', Journal of World Business, 32(4), pp. 333-350.

Welch, D.E., Steen, A. and Tahvanainen, M. (2009) 'All pain, little gain? Reframing the value of international assignments', The International Journal of Human Resource Management, 20(6), pp. 1327-1343.

Yan, A., Zhu, G. and Hall, D.T. (2002) 'International Assignments for Career Building: a Model of Agency Relationships and Psychological Contracts', Academy of Management Review, 27(3), pp. 373-391.

Zhu, H., Xia, J. and Makino, S. (2015) 'How do high-technology firms create value in international M\&A? Integration, autonomy and cross-border contingencies', Journal of World Business, 50(4), pp. 718-728. 
Table 1 The Organizational Value of International Assignments Summarised in Line With Lepak et al. (2007)

\begin{tabular}{|c|c|c|c|c|}
\hline $\begin{array}{l}\text { Example Academic } \\
\text { Perspectives }\end{array}$ & $\begin{array}{l}\text { Target or User of } \\
\text { Value }\end{array}$ & Value Content & Value Creation Process & Value Capture Process \\
\hline $\begin{array}{l}\text { RBV } \\
\text { KBV } \\
\text { Psychological } \\
\text { Contract } \\
\text { Transaction Cost } \\
\text { Economics }\end{array}$ & $\begin{array}{l}\text { Group } \\
\text { Shareholders } \\
\text { Home } \\
\text { Host } \\
\text { Assignees }\end{array}$ & $\begin{array}{l}\text { Group } \\
\text { A) Average income growth over five years, ROI, } \\
\text { pre-tax return on equity (ROE), market-to- } \\
\text { book ratio, return on assets, return on sales and } \\
\text { total stock market returns } \\
\text { B) knowledge transfer, networking capabilities, } \\
\text { internationalization, developing cultural } \\
\text { understanding, managing corruption, bringing } \\
\text { leadership skills, improved global staffing and, } \\
\text { financial gain. } \\
\text { Host } \\
\text { Labor productivity, profitability, generic business } \\
\text { performance, sales volumes, market share, } \\
\text { performance compared to parent company } \\
\text { expectations, long term subsidiary survival, ROI } \\
\text { and ROE. }\end{array}$ & $\begin{array}{l}\text { Knowledge Transfer } \\
\text { Dynamic Capabilities } \\
\text { Enabling international } \\
\text { attention }\end{array}$ & $\begin{array}{l}\text { Organizational Level } \\
\text { Isolating Factors } \\
\text { International Approach } \\
\text { Operational Needs of Subsidiary } \\
\text { HRM Practices and Retention } \\
\text { Absorptive Capacity } \\
\text { Host Maturity } \\
\text { Knowledge of Host Country } \\
\text { Competition } \\
\text { Future Employers } \\
\text { Individual Level } \\
\text { The Assignee } \\
\text { Goal Alignment } \\
\text { Other Employees } \\
\text { Societal Level } \\
\text { Institutional/Cultural Distance }\end{array}$ \\
\hline & & $\begin{array}{l}\text { Examples } \\
\text { (Daily, Certo and Dalton, 2000) } \\
\text { (Gong, 2003) } \\
\text { (McNulty, De Cieri and Hutchings, 2013) } \\
\text { (Riaz, Glenn Rowe and Beamish, 2014) }\end{array}$ & $\begin{array}{l}\text { Examples } \\
\text { (Lyles and Salk, 1996) } \\
\text { (Carpenter, Sanders and } \\
\text { Gregersen, 2000) } \\
\text { (Chung and Beamish, } \\
\text { 2005) } \\
\text { (Chang, Gong and Peng, } \\
\text { 2012) }\end{array}$ & $\begin{array}{l}\text { Examples } \\
\text { (Yan, Zhu and Hall, 2002) } \\
\text { (Gaur, Delios and Singh, 2005) } \\
\text { (Oddou, Osland and Blakeney, 2009) } \\
\text { (McNulty and De Cieri, 2011) }\end{array}$ \\
\hline
\end{tabular}




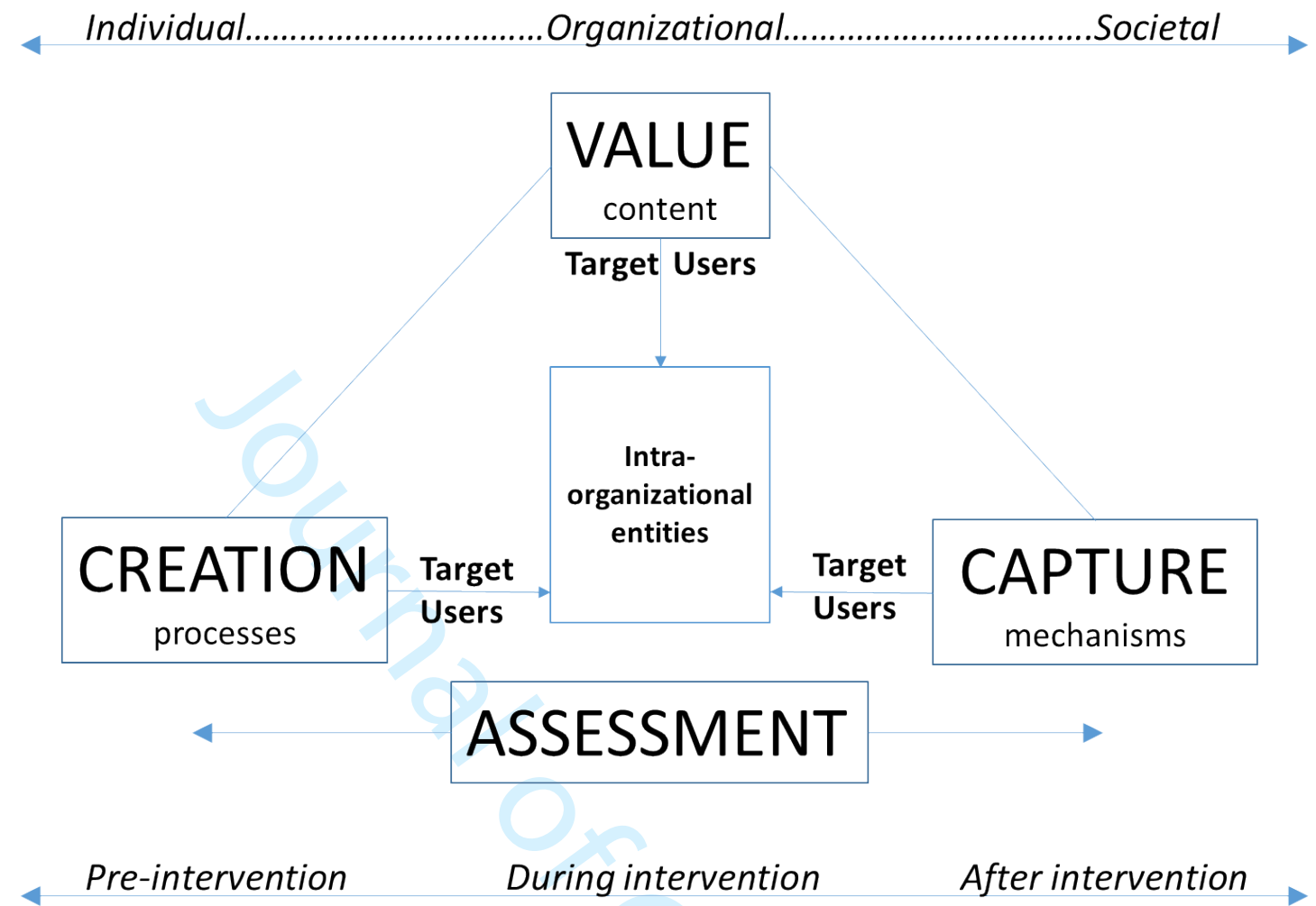

Figure 1 The Organizational Value Framework 